\title{
Modeling and optimization for rotary ultrasonic face milling of carbon fiber reinforced polymers
}

\author{
Muhammad Amin ${ }^{1,2, a}$, Songmei Yuan ${ }^{1, a}$, M. Zubair Khan ${ }^{2}$, Li Zhen ${ }^{1}$, M. Kashif Nawaz ${ }^{1}$ and Qi Wu ${ }^{1}$ \\ ${ }^{1}$ School of Mechanical Engineering \& Automation, Beihang University, Beijing, Beijing Engineering Technological \\ Research Center of High-efficient \& Green CNC Machining Process and Equipment, Beijing 100191. China \\ ${ }^{2}$ Department of Mechanical Engineering, Institute of Space Technology, Pakistan
}

\begin{abstract}
Carbon fiber reinforced polymers (CFRP) have got paramount importance in aerospace, and other industries due to their attractive properties of high specific strength, high specific stiffness, high corrosion resistance, and low thermal expansion. However, due to their properties like heterogeneity, anisotropy, and low heat dissipation, the issues in machining like excessive cutting forces and high surface roughness have found. In this research, a cutting force model has developed for rotary ultrasonic face milling of CFRP composites. The experimental machining was carried out on CFRP-T700. From the analysis, it has found that experimental and simulation values of cutting forces have variation/ error below than $10 \%$ in the most of the groups of parameters. However, the error found higher in few cases, due to heterogeneity, anisotropy and some other properties of these materials. The formula for contact area of the abrasive core tool improved and an overlapping cutting allowance has applied the first time. The optimal combination of parameters has investigated for cutting force and surface roughness. The developed cutting force model then further validated with pilot experiments and found the same results. So, the model developed in this paper is robust and can be applied to predict cutting force and optimization.
\end{abstract}

\section{Introduction and literature review}

Carbon fiber reinforced polymer composites have got a wide range of applications in aerospace, defense, and high-performance supporting equipment due to their attractive properties like high specific strength, high specific stiffness, low weight, high corrosion resistance, and low thermal expansion [1-3]. However, their properties like inhomogeneity, anisotropy, and heterogeneity, are the main hindrance for their accurate and defect free machining. Although CFRP materials are designed/ manufactured near-to-net shapes, but some machining processes including face milling are unavoidable. The cutting phenomenon is also complex for such materials and required to be investigated.

Rotary ultrasonic machining (RUM) is a nontraditional machining process which combines the material removal mechanism of diamond grinding and ultrasonic machining. A review of existing literature shows that RUM has many advantages over traditional machining, such as lower cutting forces, fewer surface defects, smaller chipping size, less subsurface damage, and less tool wear $[4,5]$.

a Corresponding author: yuansm@buaa.edu.cn, aminbuaa@yahoo.com 
Few reports have found on modeling of RUM, namely material removal rate (MRR), tool wear and rotary ultrasonic drilling. Also, some studies have found for rotary ultrasonic face milling (RUFM) of brittle materials like optical glass and ceramics. The RUFM was carried out the first time and found that the cutting forces reduce near to zero after a certain period of time [6]. The theoretical model for RUFM was developed assuming the diamond grit was spherical [7, 8]. The rotary ultrasonic face milling was then carried out with cylindrical diamond core tool for K9 optical glass and a mathematical cutting force model was developed [9]. The rotary ultrasonic face milling was carried out with conical core tool and a cutting force model for ceramic materials was developed [10].

From the literature review, it has found that a few research reports have been found for RUFM of ceramics and other composite materials. The research for rotary ultrasonic face milling of CFRP materials has not reported yet. Also, the optimized cutting force and surface roughness has not investigated till yet. So, there is an essential need to model cutting forces and to optimize cutting force and surface roughness (important for face milling). The excessive cutting forces have adverse effects on properties of composites. In this paper, the mechanistic-based cutting force model is developed to predict the cutting forces in RUFM of CFRP composites. The developed model is improved and the proportionality parameters, $K$ is obtained through designed experiments, calculations, and experimental RUFM. The analysis of variance is carried out. The optimized cutting force and surface roughness are then investigated for the first time in this paper. Conclusions are drawn in the final section.

\section{Development of cutting force model}

The cutting force model has developed by considering single abrasive grit and then applied summation for all active abrasive grits. When a diamond abrasive grit penetrates into the surface of the workpiece material, there is a plastic deformation. With the increase of penetration depth, the median cracks, and the lateral cracks grow/ generate as shown in Figure 1. The extended lateral cracks then induce and peeling off the workpiece material. The assumptions like the diamond abrasive grits/ particles are rigid regular octahedron of the same size and the material removal mode is a rigid brittle fracture, have applied.

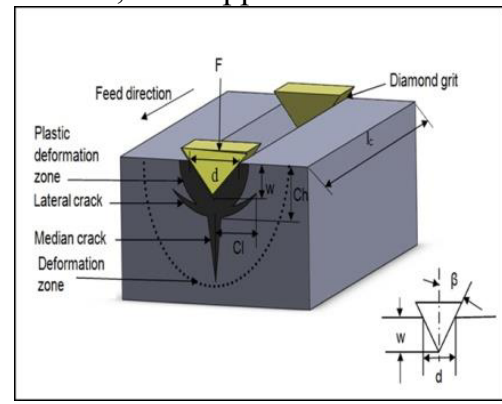

Figure 1. Crack generation in material

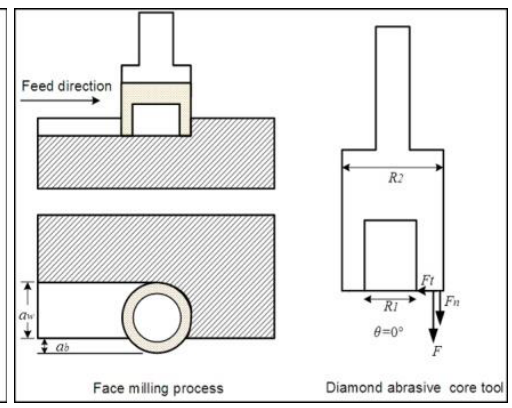

Figure 2. Face milling process

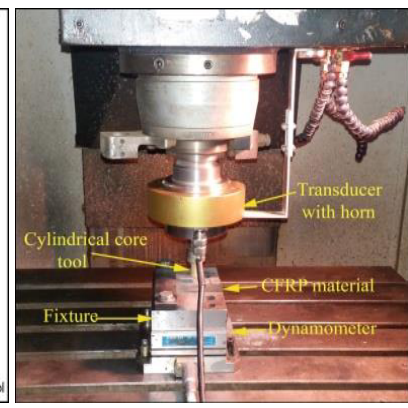

Figure 3. Experimental set up

After considering brittle fracture mechanism/ theories [11-13] and related factors, the developed cutting force model of RUFM for CFRP composites is as follows:

$$
F=\frac{K}{\cos \theta} \cdot\left[\frac{C_{3} \cdot \tan ^{26} \beta \cdot K_{I C}^{12} \cdot H_{v}^{44} \cdot\left(1-v^{2}\right)^{6} \cdot f \cdot A^{16} \cdot S_{g}^{32} \cdot f_{r}^{24} \cdot A_{0}^{8}}{\cos ^{8} \beta \cdot\left(R_{2}+R_{1}\right)^{24} \cdot E^{21} \cdot S^{24} \cdot C_{\alpha}^{32 / 3}}\right]^{1 / 35}
$$

Where $C_{3}$ is the dimensionless constant number and has value as follows:

$$
C_{3}=\left[\frac{(180)^{24}}{(0.051)^{8} \cdot C_{1}^{16} \cdot C_{2}{ }^{48} \cdot \pi^{8}}\right] \quad \text { and } C_{1}=3 \times 10^{-2} \quad C_{2}=0.226
$$

Equation (1) represents the desired cutting force prediction model for the axial cutting force. The 
contact area, $A_{0}$ can be found from Equation (2).

$$
A_{0}=\pi\left[\left(R_{2}^{2}-R_{1}^{2}\right)+R_{2}\left(a_{p}-2 a_{b}\right)-a_{p} \cdot a_{b}\right]
$$

Where, $R_{1}$ and $R_{2}$ are the inner and outer radii of the diamond core tool, respectively; $a_{p}$ is the cutting depth; $a_{w}$ is the cutting width $\left(a_{w}=R_{2}\right.$ for cylindrical core tool); and $a_{b}$ (in $\mathrm{mm}$ ) is the overlapping cutting allowance which is the distance of overlap with the machined surface by previous cutting pass of the tool (the distance which is required to leave uncut for smooth cutting surface and to reduce/ finish scallop height). Practically, it is required to be considered for accurate face milling. Also, for cylindrical core tool (Figure 2), the angle between $F$ and $F_{n}$ is zero (i.e. $\theta=0^{\circ}$ ). The other parameters related to the model have mentioned in Table 1.

Table 1. Parameters/ values related to core tool, material and cutting force model

\begin{tabular}{|c|c|c|c|}
\hline Symbol & Nomenclature & Symbol & Nomenclature \\
\hline$S_{g}$ & Side length of diamond abrasive grit, $m m$ & $\theta$ & Angle between $F$ and $F_{n},\left(^{\circ}\right)$ \\
\hline$\beta$ & Half angle of abrasive grit, $45^{\circ}$ & $H_{v}$ & Vickers-hardness of material $(0.6 \mathrm{GPa})$ \\
\hline$C_{a}$ & Abrasive concentration, $m m$ & $E$ & Elastic modulus $(53 \mathrm{GPa})$ \\
\hline$S$ & Spindle speed, $r p m$ & $K_{I C}$ & Fracture toughness, $11.5 \mathrm{MPa} \mathrm{m}^{1 / 2}$ \\
\hline$f_{r}$ & Feed rate, $\mathrm{mm} / \mathrm{min}$ & $v$ & Poisson' s ratio $(0.3)$ \\
\hline$A$ & Ultrasonic vibration amplitude, $1 \times 10^{-5} \mathrm{~m}$ & $\rho$ & Density $\left(1.8 \mathrm{~g} / \mathrm{cm}^{3}\right)$ \\
\hline$f$ & Ultrasonic vibration frequency, $1600 \mathrm{~Hz}$ & Core tool & Mesh size $40 / 45, \mathrm{metal}$ bond \\
\hline$F_{n}$ & $\begin{array}{c}\text { Axial cutting force of an abrasive on } \\
\text { the surface of the workpiece, } N(\text { newton })\end{array}$ & $C_{\alpha}$ & Concentration $(100)$ \\
\hline$F$ & $\begin{array}{c}\text { Axial cutting force ( found by cutting } \\
\text { force Dynamometer), } N\end{array}$ & $R_{2}$ & Outer radius $(6.25 \mathrm{~mm})$ \\
\hline$F_{(s)}$ & Axial cutting force simulated from model, $N$ & $R_{l}$ & Inner radius $(4.75 \mathrm{~mm})$ \\
\hline
\end{tabular}

\section{Experimental setup and conditions}

The actual experimental setup has shown in Figure 3. The setup has composed of three parts: Ultrasonic vibration system, CNC vertical machining center, and diamond core tool. The ultrasonic vibration system has an ultrasonic spindle and an ultrasonic generator. The $\mathrm{CNC}$ vertical machining center (Model: VMC 0850B, Shenyang, China) has fitted with ultrasonic vibration device/ attachment (developed by Tianjin University, China) having the ultrasonic spindle. The cutting force has measured with the dynamometer (9257B, Kistler, Switzerland). The workpiece material used in experiments was CFRP-T700 with dimensions $96 \times 40 \times 5 \mathrm{~mm}$. The properties of workpiece material and the core tool have reported in Table1. The average grit size $385 \mu \mathrm{m}$ has applied [14]. After machining, the specimens have then inspected with the non-contact 3D optical profiler (model: CCI MP by Taylor Hobson, Japan) to find roughness average (i.e., a surface roughness $\left(S_{a}\right)$ over the area and also known as the arithmetic mean height of surface) and then recorded in Table 2. Firstly, the experiments have designed by single factor experiment array with 3 factors. The level of each factor is selected by the theoretical calculations, previous experiments and keeping in view the higher values of MRR for practical/ industrial applications. For the second group, the experiments have designed on the basis of full factorial design with 2-levelof parameters, $\left(S, f_{r}\right.$, and $\left.a_{p}\right)$ by applying Minitab16.

\section{Results and discussion}

The cutting force value is the mean value of maximum values in a stable stage that has obtained through measurement in graphical form through Dynoware software. The graphical cutting force data 
then transformed to numerical data through MATLAB software and recorded in column 5 of Table 2. The simulation values and measured values of axial cutting force have found a close match with the minimum value of the factor $\sum\left(\mathrm{F}_{(m)}-K^{\prime} * F_{(s)}\right)^{2}$. This factor has differentiated with respect to $K$, putting the values for each experiment, summation of the values for all experiments, and then the value of $K$ is obtained. It is the relationship of the workpiece material and properties (geometry, material, etc.) of cutting tool. The value of $K$ has found 0.036 . The cutting force data obtained by applying the cutting force model has recorded in column 6 of Table 2.

The developed cutting force model is more close to practical machining as compared to the existing models proposed by Zhang [9], and Zhang [10]. The contact area calculations have improved in this paper and the overlapping cutting allowance, $a_{b}$ have incorporated for the results of developed model match to the practical machining situations. The maximum values of feed rate and cutting depth ( $f_{r}=180 \mathrm{~mm} / \mathrm{min}$ and $a_{p}=0.8 \mathrm{~mm}$ ) have applied to develop the cutting force model whereas the values applied by Zhang [9] are lower at considerable level $\left(f=12 \mathrm{~mm} / \mathrm{min}\right.$ and $\left.a_{p}=0.08 \mathrm{~mm}\right)$. Also, the higher values of machining parameters are required to increase the $M R R$ as, $M R R=f_{r} \cdot a_{p} \cdot a_{w}$. The cutting force has found decreased with the increase of spindle speed while found increased with the increase of feed rate and cutting depth. The same has reported by Zhang [10].

The research for rotary ultrasonic face milling of CFRP, particularly CFRP-T700 composites has been carried out first time in this paper. However, the cutting force models have also reported for RUFM of K9 optical glass and C/Sic materials [9-10].

The cutting force has found decreased with the increase of $S$ while it has found increased with the increase of $f_{r}$ and $a_{p}$ (Figure 4). Also, the measured and simulated (from the model) values of cutting force values have a close match (nearly equal). However, a variation/ error of $2.043 \mathrm{~N}(19.81 \%)$ for Exp. 12 (Table 2) has observed. From graphs of Figure 5, the surface roughness, $S_{a}$ has found increased with the increase of $S$ up to $4000 \mathrm{rpm}$ and then found decreased rapidly up to $5000 \mathrm{rpm}$. Also, $S_{a}$ has found increased with the increase of $f_{r}$ and $a_{p}$. Although, some variations from uniform curved path has been found which are due to the properties like anisotropy, and heterogeneity of CFRP material.

Table 2. Cutting force and roughness average data related to parameters

\begin{tabular}{|c|c|c|c|c|c|c|c|}
\hline $\begin{array}{c}\text { Exp. } \\
\text { No }\end{array}$ & $\begin{array}{c}S \\
(\mathrm{rev} / \mathrm{min})\end{array}$ & $\begin{array}{c}f_{r} \\
(\mathrm{~mm} / \mathrm{min})\end{array}$ & $\begin{array}{c}a_{p} \\
(m m)\end{array}$ & $\begin{array}{c}\text { Measured } \\
\text { axial force } \\
\left(F_{(m)}\right)(N)\end{array}$ & $\begin{array}{c}\text { Simulated axial } \\
\text { force }\left(F^{\prime}(s)\right. \\
\text { without } K)(N)\end{array}$ & $\begin{array}{c}\text { Simulated } \\
\text { axial force }\left(F_{(s)}\right. \\
\text { with } K)(N)\end{array}$ & $\begin{array}{c}S_{a} \\
(\mu m)\end{array}$ \\
\hline 1 & 2000 & 60 & 0.5 & 16.921 & 453.232 & 16.316 & 2.683 \\
\hline 2 & 2500 & 60 & 0.5 & 14.980 & 388.927 & 14.001 & 2.746 \\
\hline 3 & 3000 & 60 & 0.5 & 13.104 & 343.220 & 12.355 & 2.954 \\
\hline 4 & 3500 & 60 & 0.5 & 10.677 & 308.792 & 11.116 & 3.393 \\
\hline 5 & 4000 & 60 & 0.5 & 9.892 & 281.773 & 10.143 & 3.610 \\
\hline 6 & 4500 & 60 & 0.5 & 9.215 & 259.911 & 9.356 & 2.794 \\
\hline 7 & 3000 & 60 & 0.5 & 12.404 & 343.220 & 12.355 & 2.525 \\
\hline 8 & 3000 & 90 & 0.5 & 15.845 & 453.232 & 16.316 & 3.245 \\
\hline 9 & 3000 & 120 & 0.5 & 20.842 & 552.069 & 19.874 & 2.914 \\
\hline 10 & 3000 & 150 & 0.5 & 22.080 & 643.348 & 23.160 & 3.114 \\
\hline 11 & 3000 & 180 & 0.5 & 25.918 & 729.024 & 26.244 & 3.307 \\
\hline 12 & 3000 & 60 & 0.5 & 10.312 & 343.220 & 12.355 & 2.200 \\
\hline 13 & 3000 & 60 & 0.6 & 12.312 & 345.688 & 12.444 & 3.307 \\
\hline 14 & 3000 & 60 & 0.7 & 13.309 & 348.098 & 12.531 & 3.172 \\
\hline 15 & 3000 & 60 & 0.8 & 13.875 & 350.454 & 12.616 & 3.425 \\
\hline
\end{tabular}



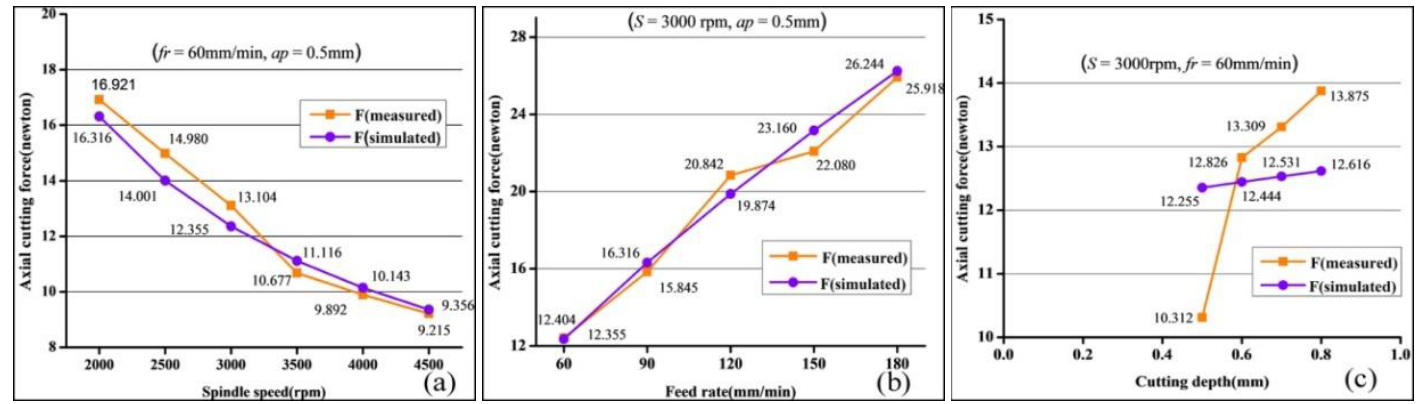

Figure 4. Relationship of cutting force and machining parameters
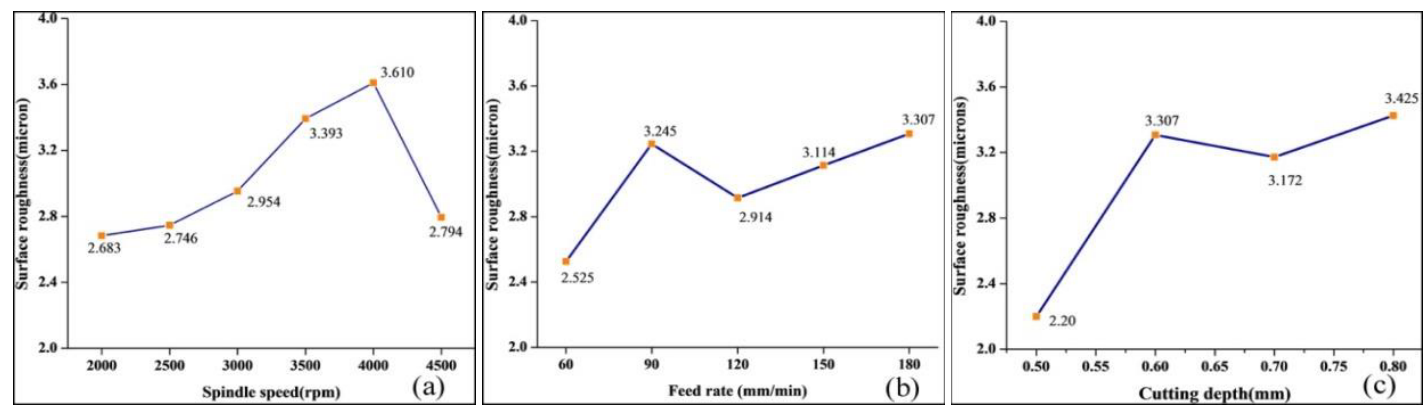

Figure 5. Relationship of surface roughness and machining parameters

\subsection{Further Analysis and Optimization}

The second group of experiments was carried out to know whether the error is random or due to some issues in cutting force model. The variation more than $10 \%$ has found in only two experiments (Exp.1 as $23.20 \%$ and for Exp.5 as $16.90 \%$ ) shown in Table 4. Such variations are mainly due to heterogeneity and anisotropy of CFRP composites. Also, these variations can rise due to uneven material properties and dislocations of fibers during RUFM. Other factors contributing to this behavior are their inhomogeneity and varying thermal behavior. So, the error up to limited level is expected and required to be accepted due to nature of the material.

The analysis of variance was carried out (Table 3) and found that $S$ and $f_{r}$ have a significant effect on $F$ while $a_{p}$ has a non-significant effect for RUFM of CFRP composites. From ANOVA for $S_{a}$, a significant and marginally significant effect has found by $S$ and $a_{p}$ respectively, while $f_{r}$ has shown a non-significant effect. From the analysis of contour plots (Figure 6), $F$ found decreased with the increase of $S$, while it increased with the increase of $f_{r}$. The optimal value of $F$ (less than $11 \mathrm{~N}$ ) can be found with $S=5000 \mathrm{rpm}, f_{r}=120 \mathrm{~mm} / \mathrm{min}$ and $a_{p}=1.2 \mathrm{~mm}$. The contour plots (Figure 7) showed that $S_{a}$ increased with the increase of cutting depth and decreased with the increase of spindle speed. The optimal value of $S_{a}$ ( less than $2.5 \mu \mathrm{m}$ ) can be found with $5000 \mathrm{rpm}$ of $S, 110 \mathrm{~mm} / \mathrm{min}$ of $f_{r}$ and 2.2 $\mathrm{mm}$ of $a_{p}$. The curvilinear profile for contour plots for $F$ and $S_{a}$ shows the quadratic model fitting.

Table 3. ANOVA for axial cutting force and surface roughness

\begin{tabular}{|l|l|l|l|l|l|l|l|}
\hline Group & Parameter & DoF & $\begin{array}{l}\text { Sum of } \\
\text { squares }\end{array}$ & Adj-mean & F-value & P-value & Finding \\
\hline \multirow{2}{*}{$\begin{array}{l}\text { Cutting } \\
\text { force }\end{array}$} & $S$ & 1 & 32.176 & 32.176 & 11.90 & 0.026 & Significant \\
\cline { 2 - 8 } & $f_{r}$ & 2 & 212.242 & 212.242 & 78.49 & 0.001 & Significant \\
\cline { 2 - 8 } & $a_{p}$ & 3 & 0.112 & 0.112 & 0.04 & 0.848 & Non-significant \\
\hline \multirow{2}{*}{$\begin{array}{l}\text { Surface } \\
\text { roughness }\end{array}$} & $S$ & 1 & 3.759 & 3.759 & 23.94 & 0.008 & Significant \\
\cline { 2 - 8 } & $f_{r}$ & 1 & 0.078 & 0.078 & 0.50 & 0.518 & Non-significant \\
\cline { 2 - 8 } & $a_{p}$ & 1 & 0.436 & 0.436 & 2.78 & 0.171 & Marginally significant \\
\hline
\end{tabular}


Table 4. Cutting force and surface roughness data

\begin{tabular}{|c|c|c|c|c|c|c|c|c|}
\hline $\begin{array}{c}\text { Exp. } \\
\text { No }\end{array}$ & $\begin{array}{c}S \\
(\text { rev } / \text { min })\end{array}$ & $\begin{array}{c}f_{r} \\
(m m / m i n)\end{array}$ & $\begin{array}{c}a_{p} \\
(m m)\end{array}$ & $\begin{array}{c}\text { Axial } \\
\text { force } \\
\left(F_{(m)}\right)(N)\end{array}$ & $\begin{array}{c}\text { Axial } \\
\text { force } \\
\left(F_{(s)} \text { without }\right. \\
K)(N)\end{array}$ & $\begin{array}{c}\text { Axial } \\
\text { force } \\
\left(F_{(s)}^{\prime} \text { with }\right. \\
K)(N)\end{array}$ & $\begin{array}{c}S_{a} \\
(\mu m)\end{array}$ & $\begin{array}{c}\text { Error } \\
\frac{\left(F_{(s)}^{\prime}-F_{(m)}\right)}{F_{(m)}} \times 100 \%\end{array}$ \\
\hline 1 & 5000 & 100 & 1.2 & 10.500 & 359.377 & 12.937 & 2.826 & +23.20 \\
\hline 2 & 3500 & 100 & 0.6 & 15.188 & 441.472 & 15.892 & 3.500 & +4.63 \\
\hline 3 & 5000 & 200 & 1.2 & 22.015 & 578.057 & 20.810 & 2.493 & -5.47 \\
\hline 4 & 5000 & 200 & 0.6 & 19.887 & 556.039 & 20.017 & 2.563 & +0.65 \\
\hline 5 & 3500 & 100 & 1.2 & 14.133 & 458.953 & 16.522 & 3.901 & +16.90 \\
\hline 6 & 3500 & 200 & 0.6 & 24.875 & 710.107 & 25.560 & 3.627 & +2.75 \\
\hline 7 & 3500 & 200 & 1.2 & 27.213 & 738.226 & 26.576 & 4.820 & -2.34 \\
\hline 8 & 5000 & 100 & 0.6 & 12.960 & 345.688 & 12.444 & 2.482 & -4.00 \\
\hline
\end{tabular}
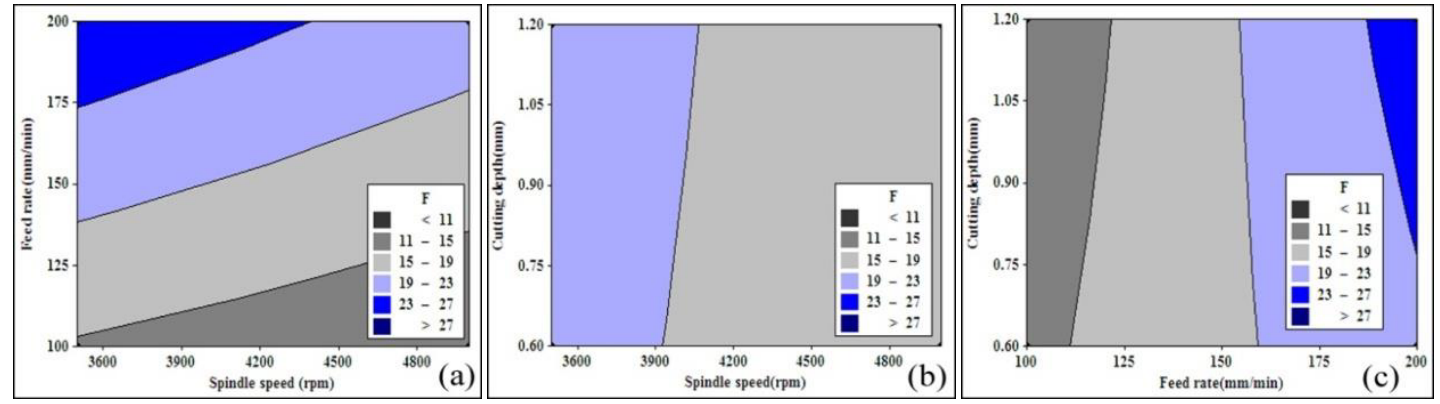

Figure 6.Surface plot for cutting force
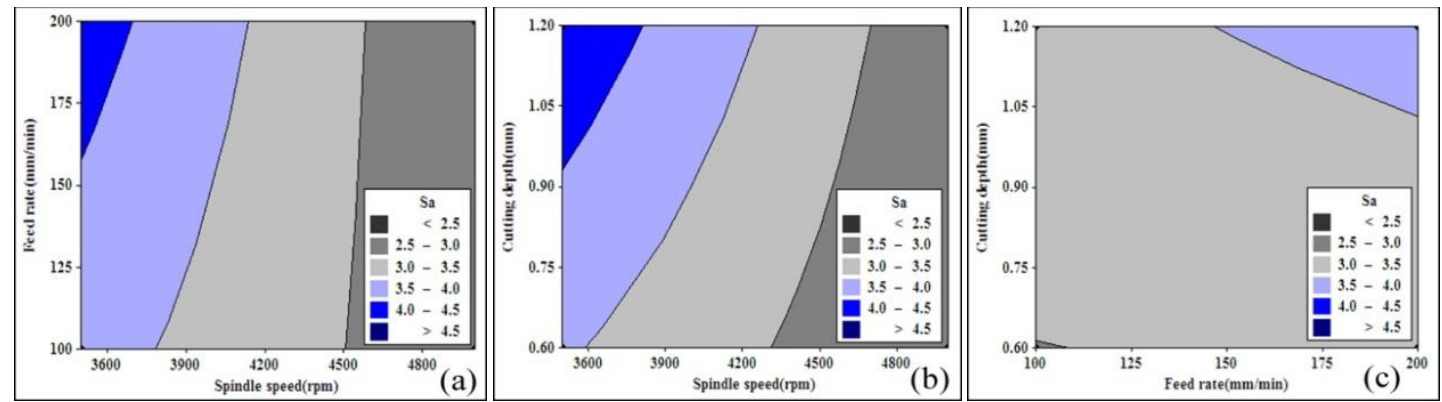

Figure 7.Surface plots for surface roughness

\section{Conclusions}

The salient features and outcomes of this research work have been recorded beneath:

1. The mechanics based cutting force prediction model has been developed for RUFM of CFRP-T700 composites. The improved formula for contact area, $A_{0}$ have been proposed in the paper and an overlapping cutting allowance, $a_{b}$ has incorporated for accurate machining. From the graphical/ numerical analysis, the measured and the simulated values of cutting forces have found a close match (nearly equal) and the percentage variation found less than $10 \%$. However, in the few cases, the variation was recorded more than this value. The cause of this variation is due to the heterogeneity, anisotropy and some other properties of CFRP composites. So, the developed cutting force model is accurate/ robust and can be applied for finding cutting forces.

2. The significantly higher values of machining parameters have applied $\left(f_{r}=200 \mathrm{~mm} / \mathrm{min} a_{p}=1.2 \mathrm{~mm}\right.$, $S=5000 \mathrm{rpm}$ ) for the first time in order to enhance $M R R$ and to close to practical machining. From 
ANOVA, $S$ and $f_{r}$ found significant for $F$ while $a_{p}$ has found non-significant. From ANOVA for $S_{a}, S$ has found significant while $a_{p}$ has found marginally significant. The $F$ and $S a$ have found decreased with the increase of spindle speed however both have found increased with the increase of feed rate and cutting depth.

3. The optimal value of $F$ (less than $11 \mathrm{~N}$ ) have found with $S=5000 \mathrm{rpm}, f_{r}=120 \mathrm{~mm} / \mathrm{min}$ and $a_{p}=1.2$ $\mathrm{mm}$. Also, the optimal value of $S_{a}$ ( less than $2.5 \mu \mathrm{m}$ ) can be found with $5000 \mathrm{rpm}$ of $S, 110 \mathrm{~mm} / \mathrm{min}$ of $f_{r}$ and $2.2 \mathrm{~mm}$ of $a_{p}$. The curvilinear profile for contour plots for $F$ and $S_{a}$ shows the quadratic model can be adequately fitted.

The developed cutting force model in this paper can be used for prediction/ minimizing of cutting forces for rotary ultrasonic face milling of CFRP composites and input resources can be saved by the increase process efficiency and quality of the product.

\section{Acknowledgment}

This research is financially supported by National High Technology Research and Development Program of China under program No. 863 with Grant No.2013AA040105. The authors are indebted to this financial support to accomplish this research.

\section{References}

1. R. M. Jones, Mechanics of composite materials. 2nd edn.Taylor \& Francis, Inc.,Philadelphia (1999).

2. A. K. Kaw, Mechanics of composite materials. $2^{\text {nd }}$ edn. Taylor \& Francis Group (2006).

3. J.Y. Sheikh-Ahmad, Machining of polymer composites. Springer science. doi:10.1007/978-0-387-68619-6 (2009).

4. J. Liu, D. Zhang, L. Qin, and L. Yan, Feasibility study of the rotary ultrasonic elliptical machining of carbon fiber reinforced plastics (CFRP). Int J Mach Tool Manuf., 53, 141-150 (2012).

5. D. Geng, D. Zhang, Y. Xu, F. He, D. Liu, and Z. Duan, Rotary ultrasonic elliptical machining for side milling of CFRP: Tool performance and surface integrity. Ultrasonics, 59, 128-137(2015).

6. Z. J. Pei, P. M. Ferreira, and M. Haselkorn, Rotary ultrasonic drilling and milling of ceramics. The design for manufacturability and manufacture of ceramic components symposium, Am cera Soc., 96 th Annual meeting (1994).

7. Z. J. Pei, and P. M, Ferreira, An experimental investigation of rotary ultrasonic face milling. Int J Mach Tool Manuf., 39, 1327-1344(1999).

8. D. J. Feng, F. L. Zhao, Z. G. Xu, and D. M. Guo, Mathematic model of material removal rate for ultrasonic milling. China Mech Eng., 17(13), 1399-1403(2006).

9. C. Zhang, J. Zhang, and P. Feng, Mathematical model for cutting force in rotary ultrasonic face milling of brittle materials. Int J Adv Manuf Technol., 69,161-170 (2013).

10. C. Zhang, S. Yuan, M. Amin, and F. Fan, Development of cutting force model based on brittle fracture for $\mathrm{C} / \mathrm{SiC}$ using rotary ultrasonic facing milling. Int $\mathrm{J}$ Adv Manuf Technol., doi: 10.1007/s00170-015-7894-4(2015).

11. D. B. Marshall, B. R. Lawn, and A. G. Evans, Elastic/plastic indentation damage in ceramics: the lateral crack system. J Am Cera Soc., 65 (11), 561-566 (1982).

12. B. R. Lawn, A. G. Evans, and D. B. Marshall, Elastic/plastic indentation damage in ceramics: the median/radial crack system. J Am Cera Soc., 63 (9-10), 574-581(1980).

13. J. A. Collins, Failure of materials in mechanical design. Wiley, New York (1981).

14. www.inlandcraft.com/uguides/lapidary_grit_chart.pdf. Accessed 15 September 2016. 